\title{
Sedentary behavior and not Physical Activity Predicts Study Progress in Distance Education`
}

Citation for published version (APA):

Gijselaers, J., Kirschner, P. A., Verboon, P., \& De Groot, R. (2016). Sedentary behavior and not Physical Activity Predicts Study Progress in Distance Education`. Learning and Individual Differences, 49, 224-229.

https://doi.org/10.1016/j.lindif.2016.06.021

DOI:

10.1016/j.lindif.2016.06.021

Document status and date:

Published: 05/07/2016

Document Version:

Peer reviewed version

Document license:

CC BY-NC-ND

Please check the document version of this publication:

- A submitted manuscript is the version of the article upon submission and before peer-review. There can be important differences between the submitted version and the official published version of record. People interested in the research are advised to contact the author for the final version of the publication, or visit the DOI to the publisher's website.

- The final author version and the galley proof are versions of the publication after peer review.

- The final published version features the final layout of the paper including the volume, issue and page numbers.

Link to publication

\section{General rights}

Copyright and moral rights for the publications made accessible in the public portal are retained by the authors and/or other copyright owners and it is a condition of accessing publications that users recognise and abide by the legal requirements associated with these rights.

- Users may download and print one copy of any publication from the public portal for the purpose of private study or research.

- You may not further distribute the material or use it for any profit-making activity or commercial gain

- You may freely distribute the URL identifying the publication in the public portal.

If the publication is distributed under the terms of Article 25fa of the Dutch Copyright Act, indicated by the "Taverne" license above, please follow below link for the End User Agreement:

https://www.ou.nl/taverne-agreement

Take down policy

If you believe that this document breaches copyright please contact us at:

pure-support@ou.nl

providing details and we will investigate your claim.

Downloaded from https://research.ou.nl/ on date: 26 Apr. 2023 


\section{Sedentary Behavior and not Physical Activity Predicts Study}

\section{Progress in Distance Education}

Hieronymus J.M. Gijselaers ${ }^{1 *}$, Paul A. Kirschner ${ }^{1}$, Peter Verboon ${ }^{2}$, Renate H.M. de Groot $^{1,3}$ http://dx.doi.org/10.1016/j.lindif.2016.06.021

Author note

${ }^{1}$ Welten Institute - Research Centre for Learning, Teaching and Technology, Open University of the Netherlands. ${ }^{2}$ Faculty of Psychology and Educational Sciences, Open University of the Netherlands.

${ }^{3}$ Maastricht University, Department of Complex Genetics, School for Nutrition, Toxicology and Metabolism (NUTRIM) / Faculty of Health, Medicine and Life Sciences, Maastricht, the Netherlands * = Corresponding author. Jérôme Gijselaers, Welten Institute, Open University of the Netherlands, P.O. Box 2960, 6401 DL Heerlen, The Netherlands. E-mail: Jerome.Gijselaers@ou.nl / h.gijselaers@gmail.com. 


\begin{abstract}
Previous research has shown that physical activity and sedentary behavior are related to learning performance in traditional education. In distance education (DE), however, students are characterized by different features (e.g., age and responsibilities). As a result, DE students often have full schedules and must make choices that traditional students do not. Advice on behavior change is low-cost and easy to implement. Therefore, it is of interest to investigate whether physical activity and sedentary behavior are related to learning performance in DE. In an observational longitudinal study, physical activity and sedentary behavior of 1100 adult DE students were analyzed using multiple regression analysis. Students provided information on physical activity, sedentary behavior and important covariates at the start of their study. Learning performance, measured as study progress, was evaluated after 14 months (i.e., the number of successfully completed modules). Analyses revealed that only sedentary behavior was a significant predictor for study progress. More sedentary behavior was predictive for more learning performance in adults participating in DE. Despite these findings, it is not recommended that students should be more sedentary as health/cognitive benefits following from more physical activity and less sedentary behavior are proven. Instead, future research should focus on which specific sedentary behaviors are responsible for this relation as sedentary behaviors may be differentially associated with learning performance.
\end{abstract}

Keywords: Learning performance; Distance learning; Online learning; The ALOUD study. 


\section{Introduction}

While physical activity has been shown to have a positive effect on academic achievement in children (Fedewa \& Ahn, 2011), sedentary behavior has been shown to have a negative effect (Tremblay et al., 2011). These findings account for children in traditional education. However, to our knowledge, there is no research that deals with the relation between physical activity / sedentary behavior and learning performance in adult students participating in distance education (DE).

This population is important as life expectancies keep rising and the fastest growing population group in most countries is that of older adults (The Netherlands: Centraal Bureau voor de Statistiek, 2014; Worldwide: United Nations, 2012). As a result of both changing policies with respect to retirement age and a rapidly changing knowledge-based economy, people also have to work and learn longer. Although certificates and diplomas usually remain valid for the entire duration of a person's life, the knowledge, skills and competencies needed in one's work change. Thus, there is an increasing need for people to develop their professional knowledge and experience far into adult age (Eurydice, 2011), often through participation in continuing formal education. An increasingly preferred form of education (both formal and informal) is DE, which allows for the liberty of studying at one's own pace and schedule. Information and Communication Technologies (ICT) and especially the Internet provide useful solutions to reach students that are not able to attend meetings during regular times or are not able to travel for the education they want. DE combines education with ICT and allows students to study at their own pace and schedule.

This study was executed among students of this type of DE, characterized by mainly online learning. The goal of this study was to evaluate whether their physical activity and/or sedentary behavior were related with their learning performance.

\subsection{Mechanisms}

Different mechanisms may be responsible for the positive effects of physical activity on learning (for a detailed overview see: Barenberg et al., 2011). Physical activity increases cerebral blood flow, the blood flowing to and through the brain. This, in turn, heightens blood supply, delivering more nutrients (e.g., glucose and oxygen) to the neurons, what may increase their function and as a result possibly enhances learning (Timinkul et al., 2008). The release and production of neurotransmitters and neurotrophins (i.e., proteins that promote development, function and survival of neurons) is also a result of physical activity (Winter et al., 2007). According to van Praag (2009), this release leads to: 
- elevated levels of neurogenesis, the process of neuron creation

- higher synaptic plasticity, the process of strengthening or weakening synaptic bonds

- higher spine density, the increase in the occurrence of possible synaptic locations

- angiogenesis, the process of creating new blood vessels from other vessels

- elevated levels of vascular growth factors, increase in factors that enhance blood vessel growth.

These neurophysiological changes are often caused by epigenetic changes (i.e., changes in the accessibility of the DNA enabling or blocking transcription) following physical activity, which lead to a higher transcription and as a result a higher release of these growth factors, neurotransmitters and neurotropic factors. The ultimate result is an increase in brain plasticity (Kaliman et al., 2011), a benefit for learning.

\subsection{Distance education versus traditional education}

Participants in this study are students of the Open University of the Netherlands (OUNL). The majority of these students has an age between 25-45, which is congruent with the typical characteristics of a DE student (Latanich, Nonis, \& Hudson, 2001). These students often have a full-time employment, a partner and children, which is logical as these characteristics are positively associated with age. This also means that their time to study is limited. This is in sharp contrast with traditional education, which is characterized by children and young adolescents, without any of these 'adult' responsibilities and constraints. This means that comparing findings on the relation between physical activity and sedentary behavior on the one hand, and learning performance between traditional and DE on the other is difficult because of differences not only in the educational setting (i.e., face-to-face vs. distance), but also differences in characteristics of the students.

\subsection{Physical activity}

There has been no research carried out dealing with the relation between physical activity and learning performance in DE. Therefore, the literature present on this relation in traditional, face-to-face education is shortly reviewed. Burkhalter and Hillman (2011) state in their review that there is no clear consensus with respect to the relation between physical activity and academic achievement in children noting that the research carried out indicates either a positive relation between physical activity and academic achievement or no relation at all. Thus, research results have been inconclusive. Despite this, physical activity is still regarded as beneficial since time spent on physical activity does not impair academic achievement (Spitzer \& Hollmann, 2013), while it improves health and physical function (Keeley \& Fox, 2009). Other research suggests that there are possible benefits of physical activity on academic achievement, but this cannot as of yet be firmly concluded (see: 
Shephard, 1996; Taras, 2005; Tomporowski, Davis, Miller, \& Naglieri, 2008). A more recent, and more comprehensive meta-analysis, executed over 59 studies of which 39 were carried out with an experimental design, revealed a significant and positive effect of physical activity on academic achievement in children, with an effect size of $0.28(S E=.03)$ which can be considered to be a small to medium effect (Fedewa \& Ahn, 2011). In other words, despite a lack of clear consensus it is safe to state that physical activity appears to have a beneficial effect on academic performance in children (see recent reviews of Hillman et al., 2011; Singh, Uijtdewilligen, Twisk, Mechelen, \& Chinapaw, 2012).

\subsection{Sedentary behavior}

The flip-side of physical activity is sedentary behavior. Sedentary behavior can actually be seen as not being physically active. However, recently it is more and more viewed as an independent construct as sedentary behavior is associated with health and demographic variables, independent of physical activity (Rhodes, Mark, $\&$ Temmel, 2012). As was the case earlier, here too, no research has been found concerning the relation between sedentary behavior and learning performance in DE. Analog to the previous section, the available literature on this relation in traditional education is shortly reviewed. A large review study found that there is a negative relation present; the more sedentary behavior exhibited by children, the lower their academic achievement (Tremblay et al., 2011). In the narrative review of 35 studies, no effect size was reported and no meta-analysis was performed. The majority (i.e., 75\%) of the studies reviewed, report that academic achievement may be hampered by what they call more screen time (i.e., watching television, playing video games, and using the computer for non-academic purposes). In interpreting these results, however, it is important to note that 32 of the 35 studies were cross-sectional in nature and academic achievement was measured in different ways (i.e., IQ, school grades, grade point average, performance on standardized tests, and self-report questionnaires) (Tremblay et al., 2011). The research in this field is in its infancy.

\subsection{The present study}

The present study evaluated the relation between physical activity and sedentary behavior on the one hand, and learning performance on the other, in students of the OUNL, offering formal university-level DE. Study at the OUNL is open to anyone over the age of 18 . This study is the first in which the relation between physical activity / sedentary behavior and learning performance - measured as study progress - is investigated in DE. Based on the literature, we propose two hypotheses: 
- Physical activity is positively associated with study progress: more time spent being physically active, or, more intense physical activity leads to better study progress.

- Sedentary behavior is negatively associated with study progress: more time spent not physically active (e.g., sitting) leads to lower study progress.

\section{Methods}

\subsection{Design}

Data from this observational study come from the Adult Learning Open University Determinants (ALOUD) study, an investigation of different psychological and biological factors possibly affecting study progress in DE students (Neroni, Gijselaers, Kirschner, \& de Groot, 2015). Data from the biological part of this project are available and stored permanently on DANS EASY, a sustainable platform for archiving research data (Gijselaers, 2015). Other measures collected in the ALOUD study but not included in this article were biological factors (e.g., sleep, nutrition), cognition, and psychological factors. Physical activity, sedentary behavior and covariates were reported via an online digital survey conducted after registration at the university. Study progress was measured objectively using data from the exam registration office.

\subsection{Participants}

During 1 year (Sept. 2012 - Aug. 2013), all new students of the OUNL who signed up for one or more regular bachelor or master course(s) were invited to participate. At the OUNL, students can register and start throughout the year as the education system used is modular and self-paced, open to everyone (with an age of at least 18 years old) and the curriculum is not fixed. The approached population size was $4945,57.5 \%$ of those approached responded $(\mathrm{N}=2842)$ and $41.3 \%$ of those approached $(\mathrm{N}=2040)$ fully participated. Included in the analyses were all participants who fully completed the survey, attempted an exam (see paragraph below), participated within 9 weeks (see section 2.3), did not make a remark that led to exclusion, and had no missing data and were not an outlier (see section 2.5). This led to a final number of 1110 students in the analyses.

Attrition rates in this population are high, as more than $50 \%$ of the responders in the investigated population did not successfully complete any course after 14 months. As the goal is to predict study progress, including students without any study progress after 14 months could confound possible relations. However, excluding those without progress is not desirable as they may have studied, but without successfully finishing a course. To make a more valid data selection, an official examination attempt was used as a proxy of having studied. In this way, the high number of students that had bought a course but never attempted to officially finish 
it or who did not intend to attain course credits (i.e., buying the course purely out of interest) could be excluded. The information on exam attempts was provided by the exam registration office.

\subsection{Procedures}

Participants were automatically invited to participate via the e-mail system of the university $14-21$ days after successful registration. The 7 days range was because a bulk mailing was sent weekly. Students received a reminder two weeks after the initial invitation and one week later a last reminder by e-mail. If after 4 weeks there was no full response recorded, the researchers called the student in which potential participants were asked whether they were still interested in participating (if the student was not reached, the researchers tried again for 3 subsequent weeks). If the response to the phone call was positive, the student received the original invitation again - if needed - and a reminder 6.5 weeks after the initial invitation, which was around 1.5 weeks after the phone call. In case the phone call was made in week 6 , the reminder was sent 1 week later. Participants only received reminders or a telephone call if no full response was recorded.

The survey was carried out online in LimeSurvey ${ }^{\circledR}$, version 1.92+ (LimeSurvey Project Team / Carsten Schmitz, 2012). Full participation cost the participants 45 to 60 minutes on average and it was possible to stop and continue later, allowing participants more room to participate by spreading the time burden. Participants who fully participated could win ( $5 \%$ chance) a gift voucher of $€ 20$. The ALOUD study was approved by the ethical review committee of the OUNL (cETO). Each participant signed a digital informed consent form, explicating the use of the personal data gathered, voluntary participation, ability to withdraw at any time, and permission to use the data for the described goals. Participants had to click a check-box to agree with the terms mentioned; a mandatory action to start the survey.

\subsection{Materials}

\subsubsection{Dependent and independent measures}

The dependent measure was the participants' objective study progress, operationalized as the number of successfully completed study modules in 14 months (i.e., the standard subscription period when registering for a course). A course at the OUNL consists of one or multiple modules. One module is equal to 4.3 European Credits (EC) in the European Credit Transfer System (ECTS). The nominal study load for one module is approximately 120 hours. The information from which the number of modules was derived came directly from the exam registration system of the OUNL. The independent measures were extracted from two separate questionnaires. Physical activity was measured using the Short Questionnaire to ASsess Health-enhancing 
physical activity (SQUASH). The SQUASH has a reasonable reliability $(r=.58)$ and validity $(r=.45)($ WendelVos, Schuit, Saris, \& Kromhout, 2003). Physical activity was calculated as a weekly activity score; an accumulated product score of intensity of the activity multiplied by the minutes spent on the activity. This way, the variable corrected for light, moderate, and vigorous activities (Wendel-Vos et al., 2003). Sedentary behavior was measured using a self-developed questionnaire based on the same design principle as used for questions in the SQUASH. Questions regarded sedentary behavior during work, transportation, leisure time (i.e., on work and free days), and resting. Sedentary behavior was calculated as a total score of minutes of sitting and lying per week.

\subsubsection{Covariates}

In the online appendix, more information can be found regarding the covariates. The online appendix provides information on how and why these variables were measured, where they originated from and how they were calculated, if relevant. The covariates taken into account were: age; sex; number of working hours per week; expected average of number of study hours per week to be invested; nationality; native language; body mass index; level of education; computer abilities; study motive; study goal; alcohol consumption; and life satisfaction.

\subsection{Analyses}

As expected, the data on the dependent measure (i.e., study progress) revealed a negative binomial distribution. Because the current study concerns part-time DE, it was expected that most students will attain an average of 2 to 3 modules per year (i.e., based on data from internal year reports). Students either completed no course at all, or, completed one, two, three or four courses. A small proportion of the sample had attained more courses, up to 20. Thus, the distribution of the dependent variable was highly skewed and resembled a negative binomial distribution. Therefore, a negative binomial generalized linear regression was conducted. A $P$-value below .05 was considered to be significant. Univariate outliers on the variables of interest (i.e., independent variables) were excluded before analyses (i.e., a standardized $Z$-value higher than the absolute value of 3.29). A covariate model was built including all covariates, after which non-significant predictors were excluded following a backward stepwise method, yielding model A. Then, model B was tested by adding the physical activity and sedentary behavior measures to model A. All analyses were performed with SPSS (version 20; SPSS Inc., Chicago, IL, USA). 


\section{Results}

\subsection{Dataset compilation}

The original dataset contained 2842 cases. Participants were excluded if they: (1) did not attempt an exam (1236 cases); (2) did not complete the survey (415 cases); (3) did not participate within 9 weeks (32 cases); (4) made a remark at the end of the survey that led to exclusion (1 case); (5) had missing values in the physical activity and sedentary behavior variables (44 cases); and (6) univariate outliers were excluded as mentioned (14 cases). All exclusions mentioned led to a total of 1100 people included in the analyses.

\subsection{Descriptives}

Table 1 provides an overview of the descriptives of all the variables, measured at the interval level. Table 2 provides an overview of the dichotomous variables. The assumption of no multicollinearity was met as the correlations between all predictors were low (i.e., below .4). This was also indicated by high tolerances (i.e., above .6; Field, 2009). All predictors (i.e., covariates and independent variables) were included in the evaluation of this assumption.

Table 1. Descriptives of all included variables measured at interval level

\begin{tabular}{lcc}
\hline Variable & Mean & $S D$ \\
\hline Study progress (successfully completed modules in 14 months) & 2.54 & 15.97 \\
Total work hours per week & 25.72 & 7.50 \\
Expected study hours per week & 13.33 & 11.02 \\
Age (years) & 35.66 & 1.37 \\
Educational level & 5.91 & 4.05 \\
Body mass index (kg/m ${ }^{2}$ ) & 23.80 & 5.80 \\
Computer abilities (scale score) & 42.79 & 2.33 \\
Expected number of attained modules & 2.25 & 5.50 \\
Total weekly alcohol consumption (standard glasses) & 3.51 & 5.47 \\
Life satisfaction (scale score) & 25.29 & 3635.98 \\
Physical activity (min/week corrected for intensity) & 7143.50 & 1368.33 \\
Sedentary behavior (min/week) & 2785.27 & \\
\hline
\end{tabular}


Table 2. Descriptives of all included variables measured at nominal or ordinal level

\begin{tabular}{lcc}
\hline Variable & Number & Percentage \\
\hline Sex & & 36.5 \\
Male & 401 & 63.5 \\
Female & 699 & 90.1 \\
Nationality & & 9.9 \\
$\quad$ Dutch & 991 & 94.8 \\
$\quad$ Non-Dutch & 109 & 5.2 \\
Native language & & \\
Dutch & 1043 & 57.0 \\
$\quad$ Non-Dutch & 57 & 43.0
\end{tabular}

\subsection{Results of the analyses}

Chi square comparisons revealed that model A was better than the null model (i.e., an intercept only model; see

Table 3), indicating that model A fits the data significantly better than the null model. Comparison of model B with model A revealed that model $\mathrm{B}$ fit the data better, $\chi^{2}(2, \mathrm{~N}=1100)=8.677, p=.01$. This means that adding both physical activity and sedentary behavior to model A predicted study progress better. When evaluating the regression weights of physical activity and sedentary behavior, the results in Table 3 show that only sedentary behavior is significant. The standardized beta for sedentary behavior is .065 which means that one standard deviation more sedentary behavior is predictive for .065 more study progress (i.e., $.065 * 4.3$ EC's per module $=$ 0.28 EC's) over 14 months.

Table 3. Generalized linear regression (negative binomial) of Model A and Model B

\begin{tabular}{|c|c|c|}
\hline Predictor variable & $\beta$ (standardized) & $\begin{array}{c}\text { Significance } \\
\text { (p-value) }\end{array}$ \\
\hline \multicolumn{3}{|l|}{ Model $A\left(\chi^{2}=83.973, \mathrm{df}=4, p<.001\right)$} \\
\hline Expected study hours & .126 & $<.001$ \\
\hline Expected number of completed modules after 6 months & .150 & $<.001$ \\
\hline Life satisfaction & .096 & $<.001$ \\
\hline Native language $^{1}$ & .567 & $<.001$ \\
\hline \multicolumn{3}{|l|}{ Model $B\left(\chi^{2}=92.650, \mathrm{df}=6, p<.001\right)$} \\
\hline Expected study hours & .131 & $<.001$ \\
\hline Expected number of completed modules after 6 months & .147 & $<.001$ \\
\hline Life satisfaction & .104 & $<.001$ \\
\hline Native language $^{1}$ & .576 & $<.001$ \\
\hline Physical activity intensity score & -.050 & .076 \\
\hline Sedentary behavior in minutes per week & .065 & .021 \\
\hline
\end{tabular}




\section{Discussion}

The aim of the present study was to examine whether physical activity and sedentary behavior were associated with study progress in DE. Sedentary behavior, but not physical activity, was associated with study progress. The results indicate that sedentary behavior appears to have a significant relation with study progress in DE, in contrast with the results obtained in traditional education. The findings are discussed separately for physical activity and sedentary behavior.

Because of theoretical underpinned mechanisms (Barenberg et al., 2011) and findings in traditional education (i.e., see reviews of Burkhalter \& Hillman, 2011 or Singh et al., 2012) positive associations between physical activity and learning performance were expected in the current study. However, results indicate that physical activity does not significantly contribute to the prediction of learning performance. First of all, it could be possible that physical activity is simply not related to learning performance in DE. However, this seems unlikely, considering the physiological processes that occur following physical activity. Therefore, we compare our population with students participating in traditional education and try to provide possible explanations. The characteristics of the DE students are that they are adult, mainly with an age between $25-45$, which is in accordance with previous research describing typical distance students (Latanich et al., 2001). In sharp contrast with traditional education, DE students often have a full-time employment, a partner and children, which means their study time is limited. Because of these time restraints it could be likely that students being more physically active spend less time studying. This could confound positive effects of physical activity as not enough is learned in the first place, meaning the physiological mechanisms cannot amplify learning as too little is learned in the first place. Furthermore, next to the differences in populations between traditional and DE, there are also differences in educational setting. Most research with children focuses on academic achievement (e.g., grades in a course, standardized test scores, etcetera). However, in the current study, learning performance was evaluated as study progress (i.e., course completion). This could lead to different results as both measures are not only different in terms of outcome, also their generation is highly different. In traditional education, students have fixed educational curricula which is in contrast with the DE investigated here as the curriculum is not fixed and students can choose any study path they prefer. Still, if both outcome measures in traditional and DE represent learning performance, more physical activity should be related to better performance in both populations. That this cannot be concluded, might then be attributable to the totally different characteristics of the two populations.

Sedentary behavior was significantly and positively predictive for learning performance, despite the hypothesized negative relation. It was shown that students with a sedentary behavior measurement of two 
standard deviations above average tend to achieve roughly a half EC extra over 14 months. Recent research recommends the measurement of specific types of sedentary behavior (Rhodes et al., 2012). It was shown that different types of sedentary behavior (e.g., working on the computer vs. watching TV) are differentially associated with cognition (Kesse-Guyot et al., 2012), which is an important predictor of learning (Diamond, 2013). In addition, in traditional education specific sedentary behaviors seem to be detrimental for learning as well, as indicated that sedentary behavior was mostly measured as TV viewing (Tremblay et al., 2011). However, research in this area is in its infancy and more research is needed to clarify possible effects or relations of sedentary behavior on or with learning. It seems to be that cognitively active sedentary behaviors (e.g., computer use for learning) have a positive influence, while other - more cognitively passive - sedentary behaviors such as TV viewing are detrimental (Rhodes et al., 2012). Unfortunately, data in the current study did not provide information on these specific types of sedentary behavior. Here, it was measured as a general total measure for sedentary behavior. This could mean that student who were more sedentary, studied more than students who were less sedentary, which would be logical as students will likely be sitting while studying. Specific types of sedentary behaviors which are differentially related to study progress in the current study could also counteract each other. This means this finding asks for further research in which different sedentary behaviors are taken into account.

The strengths of the current study are multiple. It is the first of its kind evaluating the relation between physical activity / sedentary behavior and study progress in adults participating in DE. A second aspect is that this study used a large sample providing a high power and decreasing the risk of contracting a type-1 error. Last, multiple possible confounders were controlled for, ruling out possible spurious relations. This study has also limitations. First of all, these results must be interpreted with caution as its observational design does not allow for causal inferences. Second, correctly measuring physical activity via self-administered questionnaires is an often debated topic in terms of reliability and validity (e.g., Helmerhorst, Brage, Warren, Besson, \& Ekelund, 2012). Research often shows a discrepancy between objectively and subjectively measured physical activity and/or sedentary behavior, especially in adolescents. However, in adults, a study by Slootmaker, Schuit, Chinapaw, Seidell, \& Van Mechelen (2009) using the SQUASH found reasonably good agreement. The questionnaire used in the current study highly resembles the one used by Slootmaker and colleagues (2009) as it is a modified version of the SQUASH (Wendel-Vos et al., 2003), including sedentary questions based on the principle of the SQUASH questions. Third, study progress is a fairly large-grained measure, but the best one available to measure learning performance, as grades were not possible to use because a significant number of 
courses were evaluated with a pass/fail and not with a grade. Furthermore, comparing students based on achieved credits is most reliable considering the non-fixed and modular form of education given at the OUNL. Fourth, participants had a broad time frame (i.e., 9 weeks) to participate, possibly leading to between-subject differences as some students did not yet start studying, while other were already ending their course. Last, participation took approximately 60 minutes and since participants could participate at their own pace (i.e., stop and return later) this could lead to some distortion. However, the last two points were tackled by the large dataset largely eliminating these possibly confounding factors.

We recommend future studies to replicate these findings. Concerning physical activity, we recommend future studies to control for actual study time to investigate the alternative explanation given here that physiological benefits of more physical activity are counteracted by spending less time studying. Last, concerning sedentary behavior, we recommend future studies to focus on specific sedentary behaviors to evaluate whether those are differentially related to learning.

\section{Conclusion}

Sedentary behavior, but not physical activity, was associated with study progress. The results indicate that sedentary behavior appears to have a positive relation with study progress in $\mathrm{DE}$, in contrast with the results obtained in traditional education. It is, however, unclear which type of sedentary behaviors are responsible for this relation. Important to note is that the results obtained here are applicable to adults. These results are new as there has been no research focusing on this relation in DE. The adult students served by this educational type are an increasingly important group due to their increased preference for this type of education because of the flexibility and the need for knowledge development in society and lengthening of employment age, demanding lifelong learning. It is not recommended that student should be more sedentary as research in general shows health and cognitive benefits for physical activity (Hillman, Erickson, \& Kramer, 2008) and detriments for sedentary behavior (Rhodes et al., 2012). Taking these considerations into account, it is recommended especially with regard to teachers and programs in $\mathrm{DE}$ - that students to pay attention to healthy behavior with regard to physical activity and sedentary behavior. Instead, future research should focus on which type of sedentary behaviors are related to better learning performance to clarify this relation. 


\section{References}

Barenberg, J., Berse, T., \& Dutke, S. (2011). Executive functions in learning processes: Do they benefit from physical activity? Educational Research Review, 6, 208-222. http://doi.org/10.1016/j.edurev.2011.04.002

Bernt, F. M., \& Bugbee, A. C. (1993). Study practices and attitudes related to academic success in a distance learning programme. Distance Education, 14, 97-112. http://doi.org/10.1080/0158791930140108

Burkhalter, T. M., \& Hillman, C. H. (2011). A narrative review of physical activity, nutrition, and obesity to cognition and scholastic performance across the human lifespan. Advances in Nutrition, 2, 201S-6S. http://doi.org/10.3945/an.111.000331

Centraal Bureau voor de Statistiek. (2014). Prognose bevolking 2012-2060. Retrieved from http://www.cbs.nl/nl-NL/menu/themas/bevolking/cijfers/default.htm

Church, T. S., Thomas, D. M., Tudor-Locke, C., Katzmarzyk, P. T., Earnest, C. P., Rodarte, R. Q., ... Bouchard, C. (2011). Trends over 5 decades in U.S. occupation-related physical activity and their associations with obesity. PloS One, 6, e19657. http://doi.org/10.1371/journal.pone.0019657

Crosnoe, R., \& Muller, C. (2004). Body mass index, academic achievement, and school context: Examining the educational experiences of adolescents at risk of obesity. Journal of Health and Social Behavior, 45, 393407. Retrieved from http://www.ncbi.nlm.nih.gov/pubmed/15869112

de Bie, S. E. (1987). Standaardvragen 1987: Voorstellen voor uniformering van vraagstellingen naar achtergrondkenmerken en interviews [Standard questions 1987: Proposal for uniformisation of questions regarding background variables and interviews]. Leiden: Leiden University Press.

Diamond, A. (2013). Executive functions. Annual Review of Psychology, 64, 135-68. http://doi.org/10.1146/annurev-psych-113011-143750

Eppler, M. A., \& Harju, B. L. (1997). Achievement motivation goals in relation to academic performance in traditional and nontraditional college students. Research in Higher Education, 38, 557-573. http://doi.org/10.1023/A:1024944429347

Eurydice. (2011). Adults in formal education: Policies and practices in europe. Retrieved from http://eacea.ec.europa.eu/education/eurydice/thematic_reports_en.php

Fedewa, A. L., \& Ahn, S. (2011). The effects of physical activity and physical fitness on children's achievement and cognitive outcomes: A meta-analysis. Research Quarterly for Exercise and Sport, 82, 521-535. http://doi.org/10.1080/02701367.2011.10599785 
Field, A. (2009). Discovering statistics using SPSS: And sex and drugs and rock " $n$ ” roll (Third edit). London: Sage.

Gijselaers, Dr. H.J.M. (Open Universiteit (NL)) (2015): Adult Learning Open University Determinants (ALOUD) study (biological part). DANS. http://dx.doi.org/10.17026/dans-2zy-xqju

Grady, C. L., \& Craik, F. I. (2000). Changes in memory processing with age. Current Opinion in Neurobiology, 10, 224-31. Retrieved from http://www.ncbi.nlm.nih.gov/pubmed/10753795

Halpern, D. F. (1997). Sex differences in intelligence: Implications for education. The American Psychologist, 52, 1091-1102. http://doi.org/10.1037/0003-066X.52.10.1091

Helmerhorst, H. J. F., Brage, S., Warren, J., Besson, H., \& Ekelund, U. (2012). A systematic review of reliability and objective criterion-related validity of physical activity questionnaires. The International Journal of Behavioral Nutrition and Physical Activity, 9, 103. http://doi.org/10.1186/1479-5868-9-103

Hillman, C. H., Erickson, K. I., \& Kramer, A. F. (2008). Be smart, exercise your heart: Exercise effects on brain and cognition. Nature Reviews. Neuroscience, 9, 58-65. http://doi.org/10.1038/nrn2298

Hillman, C. H., Kamijo, K., \& Scudder, M. (2011). A review of chronic and acute physical activity participation on neuroelectric measures of brain health and cognition during childhood. Preventive Medicine, 52, S21S28. http://doi.org/10.1016/j.ypmed.2011.01.024

Kaliman, P., Párrizas, M., Lalanza, J. F., Camins, A., Escorihuela, R. M., \& Pallàs, M. (2011). Neurophysiological and epigenetic effects of physical exercise on the aging process. Ageing Research Reviews, 10, 475-86. http://doi.org/10.1016/j.arr.2011.05.002

Keeley, T. J. H., \& Fox, K. R. (2009). The impact of physical activity and fitness on academic achievement and cognitive performance in children. International Review of Sport and Exercise Psychology, 2, 198-214. http://doi.org/10.1080/17509840903233822

Kesse-Guyot, E., Charreire, H., Andreeva, V. A., Touvier, M., Hercberg, S., Galan, P., \& Oppert, J.-M. (2012). Cross-sectional and longitudinal associations of different sedentary behaviors with cognitive performance in older adults. PloS One, 7, e47831. http://doi.org/10.1371/journal.pone.0047831

Latanich, G., Nonis, S. A., \& Hudson, G. I. (2001). A profile of today's distance learners: An investigation of demographic and individual difference variables of distance and non-distance learners. Journal of Marketing for Higher Education, 11, 1-16. http://doi.org/10.1300/J050v11n03_01

LimeSurvey Project Team / Carsten Schmitz. (2012). LimeSurvey: An Open Source survey tool. Retrieved from http://www.limesurvey.org 
Neroni, J., Gijselaers, H. J. M., Kirschner, P. A., \& de Groot, R. H. M. (2015). The Adult Learning Open University Determinants (ALOUD) study: Biological and psychological factors associated with learning performance in adult distance education. British Journal of Educational Technology, 46, 953-960. http://doi.org/10.1111/bjet.12288

Rhodes, R. E., Mark, R. S., \& Temmel, C. P. (2012). Adult sedentary behavior: A systematic review. American Journal of Preventive Medicine, 42, e3-e28. http://doi.org/10.1016/j.amepre.2011.10.020

Ryan, R. M., \& Deci, E. L. (2000). Self-determination theory and the facilitation of intrinsic motivation, social development, and well-being. The American Psychologist, 55, 68-78. Retrieved from http://www.ncbi.nlm.nih.gov/pubmed/11392867

Seligman, M. E. P., Ernst, R. M., Gillham, J., Reivich, K., \& Linkins, M. (2009). Positive education: Positive psychology and classroom interventions. Oxford Review of Education, 35, 293-311. http://doi.org/10.1080/03054980902934563

Shephard, R. J. (1996). Habitual physical activity and academic performance. Nutrition Reviews, 54, S32-S36. http://doi.org/10.1111/j.1753-4887.1996.tb03896.x

Singh, A., Uijtdewilligen, L., Twisk, J. W. R., van Mechelen, W., \& Chinapaw, M. J. M. (2012). Physical activity and performance at school: A systematic review of the literature including a methodological quality assessment. Archives of Pediatrics \& Adolescent Medicine, 166, 49-55. http://doi.org/10.1001/archpediatrics.2011.716

Singleton, R. A., \& Wolfson, A. R. (2009). Alcohol consumption, sleep, and academic performance among college students. Journal of Studies on Alcohol and Drugs, 70, 355-363. Retrieved from http://www.ncbi.nlm.nih.gov/pubmed/19371486

Slootmaker, S. M., Schuit, A. J., Chinapaw, M. J., Seidell, J. C., \& van Mechelen, W. (2009). Disagreement in physical activity assessed by accelerometer and self-report in subgroups of age, gender, education and weight status. The International Journal of Behavioral Nutrition and Physical Activity, 6, 17. http://doi.org/10.1186/1479-5868-6-17

Spitzer, U. S., \& Hollmann, W. (2013). Experimental observations of the effects of physical exercise on attention, academic and prosocial performance in school settings. Trends in Neuroscience and Education, 2, 1-6. http://doi.org/10.1016/j.tine.2013.03.002

Sugiyama, T., Healy, G. N., Dunstan, D. W., Salmon, J., \& Owen, N. (2008). Joint associations of multiple leisure-time sedentary behaviours and physical activity with obesity in Australian adults. International 
Journal of Behavioral Nutrition and Physical Activity, 6, 1-6. http://doi.org/10.1186/1479-5868-5-35

Taplin, M., \& Jegede, O. (2001). Gender differences in factors influencing achievement of distance education students. Open Learning: The Journal of Open and Distance Learning, 16, 133-154. http://doi.org/10.1080/02680510120050307

Taras, H. (2005). Physical activity and student performance at school. Journal of School Health, 75, 214-218. http://doi.org/10.1111/j.1746-1561.2005.00026.x

Timinkul, A., Kato, M., Omori, T., Deocaris, C. C., Ito, A., Kizuka, T., ... Soya, H. (2008). Enhancing effect of cerebral blood volume by mild exercise in healthy young men: A near-infrared spectroscopy study. Neuroscience Research, 61, 242-248. http://doi.org/10.1016/j.neures.2008.03.012

Tomporowski, P., Davis, C., Miller, P., \& Naglieri, J. (2008). Exercise and children's intelligence, cognition, and academic achievement. Educational Psychology Review, 20, 111-131. http://doi.org/10.1007/s10648007-9057-0

Tremblay, M. S., LeBlanc, A. G., Kho, M. E., Saunders, T. J., Larouche, R., Colley, R. C., ... Gorber, S. (2011). Systematic review of sedentary behaviour and health indicators in school-aged children and youth. International Journal of Behavioral Nutrition and Physical Activity, 8, 98. http://doi.org/10.1186/1479$5868-8-98$

United Nations. (2012). Population Ageing and Development 2012. Retrieved from http://www.un.org/esa/population

van Praag, H. (2009). Exercise and the brain: Something to chew on. Trends in Neurosciences, 32, $283-290$. http://doi.org/10.1016/j.tins.2008.12.007

Wendel-Vos, G. C., Schuit, A. J., Saris, W. H. M., \& Kromhout, D. (2003). Reproducibility and relative validity of the short questionnaire to assess health-enhancing physical activity. Journal of Clinical Epidemiology, 56, 1163-1169. http://doi.org/10.1016/S0895-4356(03)00220-8

Winter, B., Breitenstein, C., Mooren, F. C., Voelker, K., Fobker, M., Lechtermann, A., ... Knecht, S. (2007). High impact running improves learning. Neurobiology of Learning and Memory, 87, 597-609. http://doi.org/10.1016/j.nlm.2006.11.003 


\section{Online appendix}

The covariates measured in this study are explained in more detail in this appendix. In case English questionnaires were used, items were translated from English into Dutch by a native Dutch speaker. To make sure the translation was correct, the items were translated back by a bilingual English/Dutch-speaking person. Adjustments were made where necessary. The list below provides information on the covariates, how and why they were measured, were they originated from and how they were calculated, if relevant. The variables are:

- Age was measured as memory performance declines with increasing age (Grady \& Craik, 2000), possibly hampering learning efficiency. It was measured using the reported date of birth and was calculated in years (i.e., not rounded to integers).

- Sex was measured as sex differences in intelligence (e.g. on the domains of memory, reasoning and science) have been found which could influence study progress. There are intellectual domains where males excel females (e.g., spatial reasoning) and vice versa (e.g., verbal fluency) (Halpern, 1997).

- Number of working hours/week was measured as more working hours could lead to less study-time and consequently less study progress (Eppler \& Harju, 1997). However, research has also found that workers with fewer than 20 work hours/week perform more poorly than their counterparts working more (Taplin \& Jegede, 2001). It was calculated by adding the hours spent on work (i.e., either from wage labor or as an independent entrepreneur) and volunteering together.

- Expected average of number of study hours/week to be invested was measured as more time invested is likely to lead to better results (Bernt \& Bugbee, 1993). This was reported in hours by the participants.

- Nationality was measured as education is not 'culture free' and as such non-Dutch people could have more difficulties with the more cultural elements in the educational system. It was measured by asking whether the participant was Dutch. If not, the participant could enter his or hers nationality. These nationalities were inspected and if necessary recoded (e.g., some participants entered a region of the Netherlands as their nationality, which was recoded into Dutch). Finally, one variable indicated whether the participant was Dutch or not.

- Native language was measured as non-Dutch speakers could have more difficulties with the language of study. It was measured by asking whether the participants' native language was Dutch. If not, the participant could enter his or hers native language. These manually entered data were inspected and if necessary recoded (e.g., some participants entered a regional Dutch dialect as their native language, 
which was recoded into Dutch). Finally, one variable indicated whether the participants' native language was Dutch or not.

- Body mass index was measured as physical activity and sedentary behavior are associated with body mass index (for physical activity, see: Church et al., 2011; for sedentary behavior, see: Sugiyama, Healy, Dunstan, Salmon, \& Owen, 2008), and body mass index is negatively associated with learning performance (Crosnoe \& Muller, 2004). It was computed from self-reported weight and height, in kilogram and $\mathrm{cm}$, respectively. It was computed by the following equation: $\mathrm{BMI}=$ weight $/$ height $^{2}$ $\left(\mathrm{kg} / \mathrm{m}^{2}\right)$.

- Level of education was measured as previous level of education has been found to be a significant predictor of academic success for adult DE students (Bernt \& Bugbee, 1993). It was measured as an eight level ordinal variable following de Bie (1987). This is typical in Dutch research as these levels correspond with the education given in the Netherlands. These eight levels were: (1) primary general education, (2) lower vocational education, (3) secondary general education, (4) secondary vocational education, (5) secondary higher education, (6) higher vocational education, (7) higher general education / University education, (8) Post-graduate / post-university education. These eight categories were dummy coded into low (i.e., option 1, 2,3, and 4), high (i.e., option 5 and 6), and university level (i.e., option 7 and 8), with low as reference category.

- Computer abilities was measured as students use an electronic learning environment which could be a disadvantage when one is not very computer literate or fluent. It was measured via a self-developed Dutch questionnaire mapping attitude, confidence, and skills towards the use of a computer. Five items involved attitude, three items on confidence, and five items on skills. Six items were reversed and a four-point scale was used ranging from fully disagree to fully agree. The minimum score was 13 and the maximum score was 52. A higher score indicated better computer abilities.

- Study motive was measured as intrinsic motivation has been found to be a better motivator for learning than extrinsic triggers (Ryan \& Deci, 2000). It was indicated as either personal or professional after rescoring. The original question asked for the most important motive to start studying. Answer options were: (1) to better fulfill the requirements in my current job, (2) to enhance my chances of a new job, (3) because studying is a good way of spending leisure time, (4) I want to develop my (intellectual) capacities, (5) I want to function better at a societal or managerial level, (6) I want to know more about the subject of this course, (7) I want to develop within the respective scientific field, (8) other. Options 
$3,4,6$, and 7 were recoded as a personal motive, the others as a professional motive. Participants who entered 'other' were recoded to personal or professional based on their answer.

- Study goal was measured as it provides a clear estimation of the expectation and hence the intention of the study progress to be made. It was measured as the expected number of completed modules after 6 months, which was indicated by the participants.

- Alcohol consumption was measured as this has been found to influence study progress (Singleton \& Wolfson, 2009). It was measured as the number of standard glasses on work days and free days, which was calculated to a weekly total.

- $\quad$ Life satisfaction was measured using the 'Satisfaction with life' scale of Diener, Emmons, Larsen \& Griffin (1985) as more satisfaction has been found to be synergistic with better learning (Seligman, Ernst, Gillham, Reivich, \& Linkins, 2009). 